RESEARCH PAPER

\title{
Development of symptoms of tobacco dependence in youths: 30 month follow up data from the DANDY study
}

\author{
J R DiFranza, J A Savageau, N A Rigotti, K Fletcher, J K Ockene, A D McNeill, \\ $M$ Coleman, C Wood
}

Tobacco Control 2002;11:228-235

See end of article for authors' affiliations

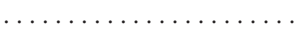

Correspondence to: Joseph R Difranza MD Department of Family Medicine and Community Health, University of Massachusetts Medical School, 55 Lake Avenue, Worcester, Massachusetts 01655, USA;

difranzi@ummhc.org

Received 27 September 2001 and revision requested 28 January 2002.

Accepted 11 March 2002

\begin{abstract}
Objective: To determine if there is a minimum duration, frequency or quantity of tobacco use required to develop symptoms of dependence.

Design and setting: A retrospective/prospective longitudinal study of the natural history of tobacco dependence employing individual interviews conducted three times annually in two urban school systems over 30 months. Detailed histories of tobacco use were obtained including dates, duration, frequency, quantity, patterns of use, types of tobacco, and symptoms of dependence.

Participants: A cohort of 679 seventh grade students (age 12-13 years).

Main outcome measures: The report of any of 11 symptoms of dependence.

Results: Among 332 subjects who had used tobacco, 40\% reported symptoms, with a median latency from the onset of monthly smoking of 21 days for girls and 183 days for boys. The median frequency of use at the onset of symptoms was two cigarettes, one day per week. The report of one or more symptoms predicted continued smoking through the end of follow up (odds ratio (OR) 44, 95\% confidence interval (CI) 17 to $114, \mathrm{p}<0.001)$.

Conclusions: Symptoms of tobacco dependence commonly develop rapidly after the onset of intermittent smoking, although individuals differ widely in this regard. Girls tend to develop symptoms faster. There does not appear to be a minimum nicotine dose or duration of use as a prerequisite for symptoms to appear. The development of a single symptom strongly predicted continued use, supporting the theory that the loss of autonomy over tobacco use begins with the first symptom of dependence.
\end{abstract}

$\mathrm{F}$ undamental gaps exist in our understanding of the neurochemical and clinical manifestations of tobacco dependence. A variety of nicotinic acetylcholine receptor types are found in tissues ranging from neurons to white blood cells. ${ }^{12}$ Nicotine acts upon many different neurotransmitter systems in various areas of the brain, but how it causes dependence is unknown. ${ }^{1}$

Clinically, it is unclear which nicotine related symptoms represent neurochemical dependence and which represent nicotine's actions on other structures or physiological functions. For example, the American Psychiatric Association (APA) considers weight gain and a reduction in heart rate following the cessation of tobacco use to be manifestations of nicotine withdrawal and therefore, of dependence, but there is no evidence that these phenomena result from the same neurophysiological processes that produce dependence. ${ }^{3}$ While it is widely accepted that dependence has a psychological component, it is not known if psychological symptoms result from a pharmacological effect of nicotine, or arise through other mechanisms such as expectations, behavioural conditioning or associative learning. ${ }^{4}$ Until a role for nicotine is established for the psychological aspects of dependence, the term "tobacco dependence" may be more appropriate for use in clinical settings. Without an understanding of its pathophysiology, it has not been possible to develop a "gold standard" for identifying or measuring nicotine dependence. ${ }^{5}$

To provide a standardised nomenclature, official committees have issued a series of definitions of nicotine dependence. ${ }^{367}$ However, these are not mutually consistent, universally accepted, or derived from addiction theory. ${ }^{8-11}$ In most definitions, nicotine dependence is characterised by tolerance, craving, withdrawal symptoms, and loss of control over the amount or duration of use. ${ }^{3467}$ Symptoms of nicotine withdrawal are said to include: craving, depressed mood, irritability, frustration, anger, anxiety, difficulty concentrating, restlessness, insomnia, headache, weight gain, and decreased heart rate. ${ }^{3} 7_{12-15}$

Even the core symptoms of nicotine dependence are debated. For example, the incentive-sensitisation model considers craving to be the central feature of dependence, but the APA has eliminated craving from its diagnostic criteria, while the World Health Organization has not. ${ }^{367916}$ The validity of tolerance as a symptom of dependence is also disputed. ${ }^{11} 1617$ Official definitions may reflect the prevailing opinion among committee members at the time, but do not represent a scientific gold standard. ${ }^{518}{ }^{19}$ Additionally, the definition of nicotine dependence in the Diagnostic and statistical manual (DSM) defines when tobacco use qualifies as a mental disorder ${ }^{3}$; it does not establish when a smoker becomes "hooked".

A recent exhaustive review of measures of nicotine dependence concluded: "the field lacks a widely accepted, theoretically derived, and psychometrically sound research tool for evaluating nicotine dependence." ${ }^{\prime 8}$ With the lack of consensus over what constitutes nicotine dependence, there has been almost no published discussion of how its first manifestations can be identified, defined or measured. ${ }^{8}$

The criteria for diagnosing nicotine dependence as a mental disorder in adults may not be very useful for identifying emerging dependence in children. By analogy, histopathological criteria for the diagnosis of alcoholic cirrhosis would serve poorly as a tool to identify the earliest histologic signs of alcoholic hepatitis.

It is in this setting of controversy and uncertainty that the Development and Assessment of Nicotine Dependence in Youth (DANDY) study sought to explore how dependence begins. Conventional diagnostic criteria for nicotine dependence were not used in the DANDY study because we were interested in determining when the first symptoms of dependence appear and when youths lose their autonomy over 
their use of tobacco. The autonomy theory holds that dependence begins when full autonomy over tobacco use is lost-that is, when the sequelae of tobacco use, either physical or psychological, present a barrier to quitting. ${ }^{20}$ The appearance of any of the symptoms of dependence considered in this report indicates a loss of autonomy..$^{20}$ The DANDY data strongly support the autonomy theory; the appearance of any single symptom of dependence was strongly predictive of failed cessation (odds ratio $(\mathrm{OR})=29$ ) and continued smoking until the end of follow up $(\mathrm{OR}=44)$, and was associated with daily smoking $(\mathrm{OR}=58)$. $^{20}$

The DANDY study addresses the question of when youths become hooked on tobacco; it does not address when youths meet the criteria for nicotine dependence as a mental disorder. ${ }^{3}$ The specific goals of the DANDY study were to determine: (1) the minimum time it takes adolescents to develop the first symptoms of dependence; (2) the minimum number of cigarettes that must be smoked each day before symptoms appear; (3) the minimum frequency of smoking below which symptoms do not occur; and (4) whether symptoms can precede the onset of daily smoking. There have been no prior studies of the onset of nicotine dependence. The literature on this topic is based on conjecture, or extrapolation from the observation of chronic smokers. ${ }^{21}$ For the past two decades, the onset of dependence has been conceptualised by the Stage Theory as a slow and sequential process, with the daily use of at least a half a pack of cigarettes as a prerequisite for dependence. ${ }^{3421-27}$ Contradicting the Stage Theory, preliminary results from the DANDY study suggested that a rapid appearance of symptoms of dependence is common. ${ }^{28}$ This report presents results from the DANDY study after 30 months of prospective data collection.

\section{METHODS}

To study the onset of the first symptoms of dependence, a cohort of 679 seventh grade students (age 12-13 years) were enrolled in a longitudinal study. Starting in January 1998, subjects were interviewed individually in school three times each year over a period of three years. This report covers the first eight rounds of interviews.

The study was conducted in two small industrial cities in central Massachusetts with populations of 38000 and 41000 in 1990, and per capita incomes below the state average. ${ }^{29}$ These cities, with a combined service and industrial economic base, provide a rich mix of ethnic, cultural, and racial backgrounds. The study population was $68 \%$ non-Hispanic white, 20\% Hispanic, 5\% Asian, 4\% African American;,0.6\% Native American; and 2.5\% unspecified. Among the white population, French and Italian ancestry were common. The socioeconomic status of the population covered the spectrum from poor to affluent.

There were 900 seventh grade students in the seven public schools in these two cities when the study began in January 1998. The following factors contributed to the selection of these cities: their large and ethnically diverse student bodies, the cooperation of the school administrations, and smoking rates comparable to the national average. ${ }^{30}$

As this is a descriptive study, the sample size was determined by a desire to produce reasonably precise estimates of all important descriptive statistics. Based on prior surveys, it was anticipated that $60 \%$ of subjects would try smoking and $30 \%$ would use it regularly. An assumed worst case attrition rate of $40 \%$ indicated an initial sample size of 650 was needed. With the approval of our institutional review board, the parents of all seventh graders were given the opportunity to withdraw their child from participating. Random number assignments were used to recruit 650 subjects. Prior tobacco use did not preclude participation. The initial 650 interviews were completed ahead of schedule
Table 1 Survey items concerning symptoms of dependence. The first 10 items constitute the Hooked On Nicotine checklist

1) Have you ever tried to quit, but couldn't?

2) Do you smoke now because it is really hard to quit?

3) Have you ever felt like you were addicted to tobacco?

4) Do you ever have strong cravings to smoke?

5) Have you ever felt like you really needed a cigarette?

6) Is it hard to keep from smoking in places where you are not supposed to, like school?

When you tried to stop smoking . . . (or, when you haven't used tobacco for a while...

7) did you find it hard to concentrate because you couldn't smoke?

8) did you feel more irritable because you couldn't smoke?

9) did you feel a strong need or urge to smoke?

10) did you feel nervous, restless or anxious because you couldn't smoke?

11) did you feel sad, blue, or depressed because you couldn't smoke?

allowing the sample size to be expanded to 679. Subjects were told the study concerned tobacco, and was confidential. This report covers the period January 1998 to June 2000.

A continuous record was maintained concerning demographic data, prior and current tobacco use, including the duration, frequency, amount, and pattern of use, the types of tobacco used, periods of abstinence, attempts to quit, and parental smoking status as reported by the subjects. The maximum rate of consumption was recorded and converted to units of days/year and cigarettes/year. Subjects were asked to provide exact dates for the first puff, inhalation, monthly use, and daily use, as well as the first occurrence of 11 symptoms of dependence (table 1).

A literature review located validated survey items used to identify dependence in previous studies. ${ }^{12}{ }^{31-36}$ The 11 items listed in table 1 have been evaluated for their psychometric properties when used as a scale to measure the loss of autonomy over tobacco use. ${ }^{20}{ }^{37}$ The item concerning sadness did not perform as well as the other 10 items, either in the DANDY study, or another by O'Loughlin and colleagues, but it was retained here as that was the initial study design. ${ }^{20}{ }^{37}$ The autonomy theory of tobacco dependence states that the appearance of a single symptom of dependence indicates a loss of autonomy over tobacco use. As a test of the autonomy theory, the Hooked on Nicotine Checklist (HONC) was formed from the first 10 items in table $1 .^{20}$ The HONC has an internal reliability of $0.94 . .^{20} \mathrm{~A}$ one factor solution explains $66 \%$ of the total variance. The number of HONC symptoms correlates with the maximum amount smoked $(r=0.65, \mathrm{p}<0.001)$, and the maximum frequency of smoking $(r=0.79$, $\mathrm{p}<0.001) .{ }^{20}$ Focus group testing has established that youths understand the HONC items in the same way as adults do. ${ }^{38}$

Structured interviews were conducted individually and privately in the schools three times annually. Four techniques proven to facilitate the accurate recall of dates and events were employed during interviews. ${ }^{39} 40$ These included the use of personal landmarks, bounded recall, decomposition, and a visual aide in the form of a personalised calendar. ${ }^{39}{ }^{40}$ A calendar of significant events was created for each tobacco user and brought to each interview to serve as a memory aide and to assist in establishing the timing and sequence of events. Specific dates for smoking activities or symptoms were recorded when available. Otherwise, if an event was recalled to have occurred at the beginning of the month, it was recorded as the 7 th of the month, the middle as the 15 th, and the end of the month as the 25 th.

Subjects who had used any form of tobacco were termed tobacco users and the date of first use was when a subject first puffed or used smokeless tobacco. A subject was termed a 
Table 2 Cumulative symptoms of nicotine dependence among 332 young adolescents who had ever tried tobacco

\begin{tabular}{|c|c|c|c|c|c|}
\hline Symptoms of nicotine dependence & $\begin{array}{l}\text { Percentage } \\
\text { reporting } \\
\text { symptom (n) }\end{array}$ & $\begin{array}{l}\text { Percentage of } 183 \\
\text { boys reporting } \\
\text { symptom }(n)\end{array}$ & $\begin{array}{l}\text { Percentage of } 150 \\
\text { girls reporting } \\
\text { symptom (n) }\end{array}$ & $\begin{array}{l}\text { Odds ratio with } \\
\text { boys as the } \\
\text { reference value }\end{array}$ & $\begin{array}{l}\mathrm{p} \text { Value for sex } \\
\text { comparison }\end{array}$ \\
\hline $\begin{array}{l}\text { 1) Failed quit attempt } \\
\text { 2) Really hard to quit } \\
\text { 3) Felt addicted } \\
\text { 4) Strong cravings } \\
\text { 5) Really needed a cigarette } \\
\text { 6) Hard to refrain }\end{array}$ & $\begin{array}{l}23(75) \\
11(35) \\
21(68) \\
28(93) \\
31(103) \\
13(44)\end{array}$ & $\begin{array}{l}19(35) \\
7(12) \\
17(31) \\
18(32) \\
22(40) \\
9(16)\end{array}$ & $\begin{array}{l}27(40) \\
15(23) \\
25(37) \\
41(61) \\
42(63) \\
19(28)\end{array}$ & $\begin{array}{l}1.5 \\
2.6 \\
1.6 \\
3.2 \\
2.6 \\
2.4\end{array}$ & $\begin{array}{l}\text { NS } \\
<0.01 \\
\text { NS } \\
<0.001 \\
<0.001 \\
<0.01\end{array}$ \\
\hline $\begin{array}{l}\text { When you tried to stop smoking ... } \\
\text { 7) Hard to concentrate } \\
\text { 8) Irritable } \\
\text { 9) Strong need or urge } \\
\text { 10) Nervous, restless or anxious } \\
\text { 11) Sad, blue or depressed }\end{array}$ & $\begin{array}{l}18(60) \\
21(70) \\
25(84) \\
21(70) \\
11(35)\end{array}$ & $\begin{array}{l}15(28) \\
16(29) \\
18(33) \\
17(30) \\
7(13)\end{array}$ & $\begin{array}{l}21(32) \\
27(41) \\
34(51) \\
27(40) \\
15(22)\end{array}$ & $\begin{array}{l}1.5 \\
2.0 \\
2.3 \\
1.8 \\
2.3\end{array}$ & $\begin{array}{l}\text { NS } \\
<0.02 \\
<0.001 \\
<0.05 \\
<0.05\end{array}$ \\
\hline
\end{tabular}

monthly smoker if he or she had ever smoked on two days within any 60 day period, representing a minimum frequency of use of one day per month. The onset of monthly smoking was taken as the date of the second day of smoking within the 60 day period. Thus, a subject who smoked his first two cigarettes on Monday and his third on Tuesday would be a monthly smoker on Tuesday, the second day of smoking, even though a month had not passed. All subjects who smoked on two or more days within any 60 day period (including daily smokers) would be monthly smokers. Tobacco dependence symptoms were operationally defined as follows: loss of control over the amount or duration of use as indicated by items 1 and 2 in table 1; an admission of feeling addicted to tobacco (item 3); craving or needing tobacco (items 4 and 5); difficulty controlling the behaviour as indicated by a positive response to item 6; or self report of any of the symptoms of nicotine withdrawal shown in table 1 (items 4, 7-11).

The first puff on a cigarette was before kindergarten for several subjects, and often, several years passed between the first and second cigarettes. The initiation of monthly smoking was thus judged to be a more meaningful baseline for measures of latency. The latency from the onset of monthly smoking to the first symptom of dependence was measured in days and is reported in completed 30 day months in the figures. If symptoms preceded monthly smoking, the latency had a negative value. Subjects with negative latency values, and those reporting symptoms within the first month, are graphed at a latency of zero completed months. For the question "Do you smoke now because it is really hard to quit?" the date recorded was the date of the interview, not the date when it first became hard to quit.

The Student's $t$ test and the Mann-Whitney $U$ test were used to compare means for normally distributed data and mean ranks for skewed data, respectively. Standard deviations (SD), standard errors (SE), odds ratios (OR), and 95\% confidence intervals (CI) are reported. The $\chi^{2}$ was used to examine the relation between discrete variables. Logistic regression analysis and analysis of covariance were used to examine the role of sex as it was related to the number of symptoms of dependency while controlling for other factors such as age at first use or age at the time of monthly use. ${ }^{41} \mathrm{~A}$ probability value of $p<0.05$ was used as a test of significance (NS, not significant).

\section{RESULTS}

Eight interviews were completed by 471 subjects (70\%). The data presented include all 679 subjects in the initial cohort. The mean follow up was 728 days. The sample was $51 \%$ male, with a mean initial age of 13.1 years (range 12-15 years).

Prior use of tobacco was reported by 255 subjects (38\%) at the first interview. Over the course of follow up, 332 (49\%) had used some form of tobacco, $315(47 \%)$ had puffed on a cigarette, $135(20 \%)$ had puffed on a cigar, and $25(4 \%)$ had tried spit tobacco. There were no regular users of cigars or spit tobacco.

Attrition rates did not differ by sex (females 32\%, males $29 \%, \chi^{2}=0.44$, NS). Attrition rates were higher for subjects who had a mother that had smoked (current smoker $39 \%$, former smoker $29 \%$, non-smoker $24 \%, \chi^{2}=13.4$, p < 0.001 ), or a father who had smoked (current smoker $35 \%$, former smoker $29 \%$, non-smoker $22 \%, \chi^{2}=9.1, \mathrm{p}<0.01$ ). Attrition rates were also higher for subjects that reported using tobacco before the first interview (38\%) compared to subjects that had not smoked previously $\left(26 \%, \chi^{2}=10.1, \mathrm{p}<0.005\right)$.

Our subjects were in the eighth grade during academic year 1998-99. By the middle of the school year, $38.4 \%$ had tried a cigarette and $6.6 \%$ reported daily use, compared to national figures of $44.1 \%$ and $8.1 \%$, respectively. ${ }^{42}$ Tobacco use rates may have been lower than the national figures because of a greater attrition rate among our subjects that had used tobacco or were at higher risk for tobacco use because of parental smoking.

The mean age for the first use of tobacco was 11.7 years, and for the first monthly use 12.8 years. Inhaling on a cigarette was reported by 237 subjects ( $35 \%$ ), with 145 ( $21 \%$ of the total population) progressing to monthly use, and 91 (13\% of the total population) progressing to daily use. The mean latency from first use to daily use was 766 days with no significant sex differences (median 696 days, range 0-3601 days, $\mathrm{SD}=751$, $\mathrm{n}=89$ ). The mean latency from first use to monthly use was 486 days (median 158 days, range 0-3601 days, $\mathrm{SD}=700$, $\mathrm{n}=144$ ), and from monthly use to daily use, 251 days (median 70 days, range $0-1287$ days, $S D=326, \mathrm{n}=89$ ). Out of 332 subjects who had used any form of tobacco, when last interviewed, 75 (23\%) were currently smoking, 54 (16\%) had quit within the past three months, and 203 (61\%) had quit for longer than three months.

Among the 332 subjects who had ever used tobacco, even just a puff, $132(40 \%)$ reported symptoms of dependence, with a mean of 2.3 symptoms per subject (table 2 ). Among subjects who reported inhaling $(\mathrm{n}=237), 53 \%$ reported symptoms, with a mean of 3.1 symptoms per subject ( $S D=0.25$ ). Strong cravings and needing a cigarette were the most commonly reported symptoms.

The frequency of use at the time of the first symptom was recorded for 125 subjects. Considering only subjects who had reported symptoms, $18 \%$ reported symptoms soon after their first use. Cumulatively, 33\% reported symptoms when smoking at a rate of one day per month, $49 \%$ when smoking one day per week, and $70 \%$ before the onset of daily smoking (fig 1). The appearance that daily smoking is a significant milestone is an artefact of the ceiling effect inherent in measuring the smoking rate in units of days per week (fig 1). Many 


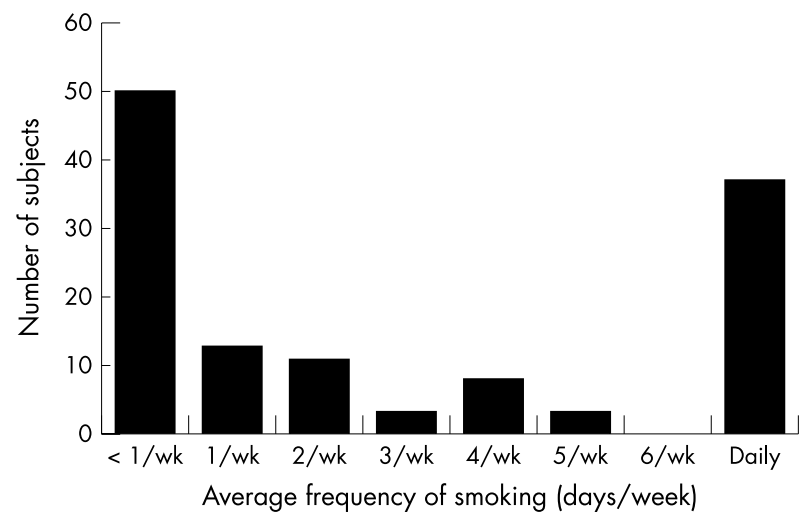

Figure 1 Average frequency of smoking at the time when the first symptom of dependence was experienced by 125 young adolescent smokers.

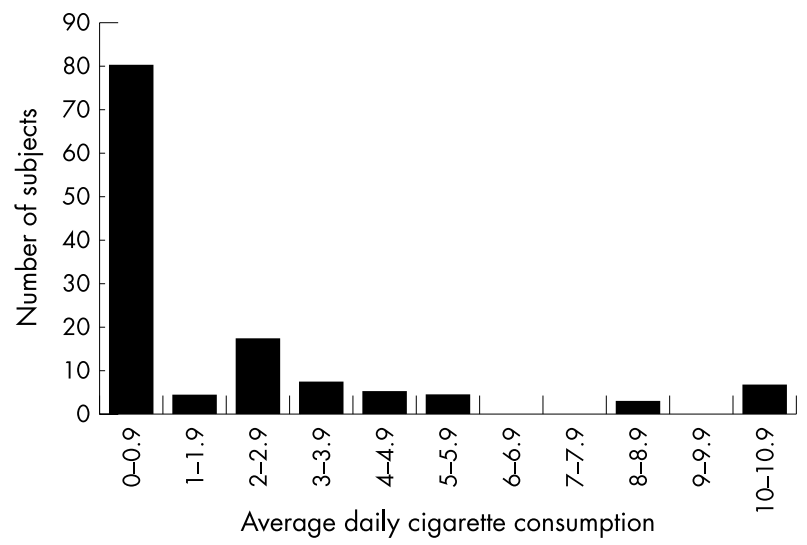

Figure 2 Average daily cigarette consumption reported at the time when the first symptom of nicotine dependence was experienced among 125 young adolescents.

subjects who developed symptoms after initiating daily smoking did not do so until they were smoking several cigarettes per day (fig 2). In fig 2, it can be seen that the transition from smoking less than one cigarette per day to smoking one cigarette per day is not associated with a jump in the number of smokers reporting first symptoms. Nor is the smoking of a half pack per day (10 cigarettes). Ninety five per cent of symptomatic subjects reported symptoms before smoking a half pack per day. Out of 125 symptomatic subjects, a cumulative $52 \%$ reported symptoms by the time they were smoking

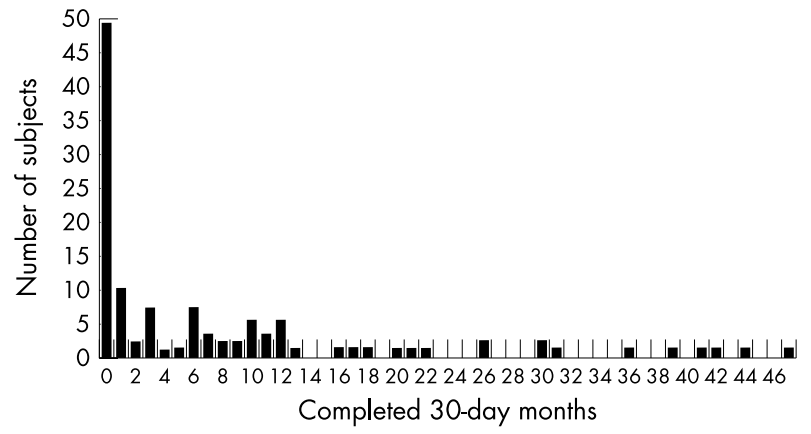

Figure 3 Incidence of initial symptoms of nicotine dependence in 125 of 332 adolescents who had ever used tobacco according to the number of 30 day months completed from the onset of monthly smoking.

an average of two cigarettes per week, and $65 \%$ by the time they averaged one cigarette per day. The mean level of consumption at the onset of symptoms was 583 cigarettes/ year $(S D=945)$ with no significant sex differences. Parental smoking history was not significantly related to the frequency of smoking at the onset of symptoms. Taken together, the frequency and quantity data suggest that about half of the symptomatic youths had experienced symptoms by the time they were smoking two cigarettes in one day each week, and that about two thirds had symptoms by the time they were smoking one cigarette per day.

As depicted in fig 3, the time elapsed from the onset of monthly smoking to the first symptom was typically very short. Table 3 presents latency data for each of the 11 symptoms. It can be seen that the time course for the development of each of the symptoms is similar, indicating that the rapid onset of symptoms is not being driven by one, or a few symptoms. Subjects occasionally reported symptoms before smoking monthly. Latencies were calculated in terms of the number of days that had transpired from the onset of monthly smoking to the development of the first HONC symptom. The median latency was 54 days (mean (SD) 189 (427) days, range -1049 to 2025 days). As depicted in fig 4, girls reported a much faster onset of symptoms than did boys. Among subjects who reported symptoms, the median latency was 21 days for girls (mean 290 (448) days, range -609 to 2025 days) and 183 days for boys (mean 110 (396) days, range -1049 to 1329 , Mann-Whitney U test, $\mathrm{Z}=-2.8, \mathrm{p}<0.005)$.

Significant sex differences were seen also in the number of symptoms reported (table 2). Each of the 11 symptoms was reported by a greater proportion of girls than boys, with the differences reaching significance for eight symptoms. Among

Table 3 Latency period between the onset of monthly smoking and the appearance of the listed symptoms of dependence among 332 youths who had ever tried tobacco

\begin{tabular}{|c|c|c|c|c|c|c|c|c|}
\hline Symptoms & $\begin{array}{l}\text { Total number of } \\
\text { smokers reporting } \\
\text { this symptom }\end{array}$ & $\begin{array}{l}\text { Median latency from } \\
\text { monthly smoking to } \\
\text { symptom onset (days) }\end{array}$ & $\begin{array}{l}\text { Mean } \\
\text { latency } \\
\text { (days) }\end{array}$ & $\begin{array}{l}\text { SD } \\
\text { (days) }\end{array}$ & Range (days) & $\begin{array}{l}1 \text { st quartile } \\
\text { (days) }\end{array}$ & $\begin{array}{l}\text { 2nd quartile } \\
\text { (days) }\end{array}$ & $\begin{array}{l}\text { 3rd quartile } \\
\text { (days) }\end{array}$ \\
\hline 1) Failed quit attempt & 74 & 219 & 359 & 366 & -212 to $1440^{*}$ & 86 & 218 & 528 \\
\hline 2) Really hard to quit† & 34 & 589 & 630 & 369 & 75 to 1597 & 366 & 587 & 845 \\
\hline 3) Felt addicted & 66 & 215 & 378 & 417 & 0 to 1502 & 32 & 187 & 620 \\
\hline 4) Strong cravings & 86 & 141 & 277 & 389 & -500 to 1484 & 20 & 131 & 447 \\
\hline 5) Really needed a cigarette & 91 & 179 & 241 & 393 & -1049 to 1287 & 15 & 179 & 439 \\
\hline 6) Hard to refrain & 43 & 316 & 424 & 487 & -292 to 2025 & 99 & 316 & 608 \\
\hline 7) Hard to concentrate & 57 & 215 & 393 & 419 & -292 to 1502 & 62 & 215 & 570 \\
\hline 8) Irritable & 68 & 213 & 366 & 416 & -487 to 1502 & 51 & 197 & 608 \\
\hline 9) Strong need or urge & 79 & 202 & 364 & 432 & -710 to 1707 & 54 & 202 & 547 \\
\hline 10) Nervous, restless or anxious & 68 & 330 & 371 & 404 & -609 to 1707 & 61 & 304 & 522 \\
\hline 11) Sad, blue or depressed & 34 & 200 & 389 & 516 & -547 to 1430 & 61 & 194 & 861 \\
\hline
\end{tabular}

*Negative numbers indicate that the symptom preceded the onset of monthly smoking

†The wording of this item is "do you smoke now because it is really hard to quit?" The dates associated with this item represent the date of the interview and not the date when the symptom first appeared. 


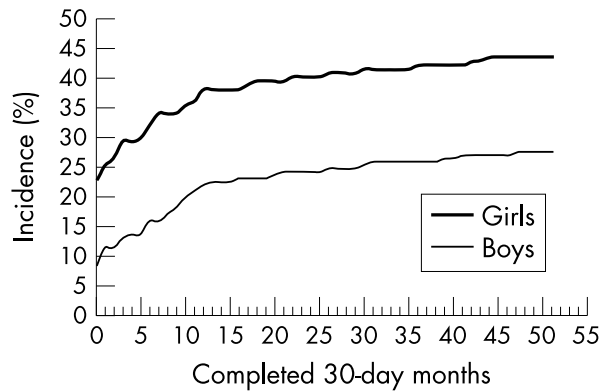

Figure 4 Cumulative incidence of symptoms of nicotine dependence among 332 young adolescents who had ever used tobacco. Subjects who reported symptoms within the first month of tobacco use are plotted at zero completed months.

all subjects who had tried tobacco, girls reported an average of 2.9 symptoms compared to 1.6 for boys $(t=-3.31, \mathrm{p}<0.001)$. Among those who had progressed to monthly smoking, girls had a mean of 5.7 symptoms ( $\mathrm{SE}=0.43,95 \% \mathrm{CI} 4.9$ to 6.6 ) compared to 4.0 for boys ( $\mathrm{SE}=0.44,95 \%$ CI 3.1 to 4.9 ) after adjusting for age at the onset of monthly smoking using an analysis of covariance methodology $(p<0.05)$. There was no significant sex difference in the latency from first use to daily smoking ( $\mathrm{n}=89$, mean 767 days, males 700 days, females 829 days, $\mathrm{SD}=751, \mathrm{t}=-0.81, \mathrm{p}=0.4$ ).

An analysis was performed to determine whether a report of a single symptom was predictive of continued smoking until the end of follow up. Among 332 subjects who had ever used tobacco, those who, at any time during the study, had reported any of the 11 symptoms of dependence were more likely to have been current smokers at their last interview $\left(\mathrm{OR}=44,95 \%\right.$ CI 17 to $\left.114, \chi^{2}=116, \mathrm{p}<0.0001\right)$.

\section{DISCUSSION}

Symptoms of tobacco dependence were quite prevalent among this young population, with symptoms being reported by $40 \%$ of those who had tried tobacco and by $53 \%$ of youths who had inhaled. There did not appear to be any minimum frequency or amount of use required for symptoms to occur. Symptoms after a few exposures were common, confirming our preliminary report. ${ }^{28}$

The subjects in this study were not diagnosed as nicotine dependent based upon DSM criteria. ${ }^{3}$ We have proposed an alternative approach to assessing dependence, one that is derived from the autonomy theory. ${ }^{20}$ Our data suggests that the loss of autonomy in adolescents frequently occurs rapidly and at very low levels of nicotine exposure. ${ }^{28}$ The median consumption at the time of the first symptom was two cigarettes per week.

Symptoms of dependence apparently precede the development of chronic tolerance in most smokers. Before the development of chronic tolerance, smokers can satisfy their needs with only an intermittent cigarette and might feel little need to light up within five minutes of arising or smoke when sick in bed. Daily smoking and half pack per day smokingbehaviours which are clearly related to dependence in chronic adult smokers-showed no relation to the development of symptoms of dependence in our subjects.

The onset of symptoms has never been studied in adult onset smokers, so we are unable to comment on whether symptoms develop more quickly or at lower levels of consumption in adolescents or adults. But a significant body of evidence suggests that adolescents are more vulnerable to nicotine dependence. Brain development continues into adolescence, and perhaps because of this, the adolescent brain appears to be more vulnerable to nicotine. ${ }^{43-48}$ Individuals who begin smoking during adolescence are more likely to become dependent, to progress to daily smoking, to continue to smoke into adulthood, to smoke for a greater number of years, and to smoke more heavily as adults. ${ }^{25}{ }^{49-53}$ Adolescents under 19 years of age are twice as likely to report difficulty quitting before smoking 100 cigarettes than are individuals of $19-22$ years. ${ }^{31}$ Proven smoking cessation approaches have had disappointing results with adolescent smokers. ${ }^{54} 55$

The animal data also support a conclusion that adolescents are more vulnerable to nicotine. Nicotine infusions in rats result in the up-regulation of midbrain nicotinic acetylcholine receptor binding to a much greater extent in the adolescent than in the adult. ${ }^{56}$ Furthermore, this change is more persistent in the adolescent: one month into withdrawal, midbrain receptors are still significantly up-regulated in adolescents, but not in adults. ${ }^{56}$ In adolescent rats, nicotine induces cell damage in the hippocampus, and in both mice and rats, adolescents demonstrate greater impairment in reward system function after nicotine exposure..$^{56-60}$ In parallel with the synaptic changes, nicotine has different, and sometimes opposite, behavioural effects in adolescent and adult animals. ${ }^{61}{ }^{62}$

Together, the human and animal data suggest that juvenile onset nicotine dependence may differ in important ways from the dependence that results from exposing neurophysiologically mature individuals to nicotine. The current literature would support speculation that juvenile onset nicotine dependence may represent a more serious disruption of neurological functioning. ${ }^{56-59}$

It seems incredible that dependence might begin so quickly. What mechanisms might be operating? The calming effect of nicotine (thought to be mediated by the right hemisphere) is the primary reason given by adolescents for smoking. ${ }^{33}{ }^{63-66}$ Some non-smoking youths appear to feel a need to self medicate symptoms of stress and turn to tobacco for this reason. If youths turn to tobacco to cope, it should not be surprising that some will develop an immediate psychological dependence. However, this cannot be the full explanation for the rapid onset of symptoms, since youths also quickly develop withdrawal symptoms that presumably indicate a physiological dependence. Animal experiments indicate that the neurochemical changes brought about by nicotine can develop quite rapidly. A dose of nicotine equivalent to a single cigarette produces long term potentiation of dopamine neurons in the ventral tegmental reward area, suggesting that the very first dose of nicotine "can leave its mark in the brain for a long time". ${ }^{67}$

Nicotine causes an increase in the number of high affinity nicotinic cholinergic receptors in the brain structures associated with the reward pathway in both humans and rodents, an effect which is thought to play a role in addiction. ${ }^{26-74}$ The increase in receptor numbers parallels the development of tolerance, and receptor numbers decline after the drug is stopped, coinciding with withdrawal symptoms. ${ }^{687174}$ Mice lacking the high affinity nicotinic cholinergic receptor will not self administer nicotine, suggesting that it is involved with the drug's rewarding properties. ${ }^{72}$ Nicotine infusions result in maximal up-regulation of receptors in just four days in mice, and in 10 days in rats. ${ }^{70}{ }^{71}$ The up-regulation of nicotinic receptors has not been established as a mechanism causing nicotine dependence, but the rapidity with which these changes in brain structure develop makes it plausible that the first physiological symptoms of dependence might also appear quickly.

Consideration was given to possible methodological problems as an explanation for our results. To evaluate the possibility that repeated interviewing might result in prompting, the latency to symptoms was compared for subjects who reported symptoms at the first interview and for those who reported symptoms only after repeated interviews. ${ }^{28}$ There was no evidence that any significant prompting occurred; very short latencies were reported at the first interview. ${ }^{28}$

Many subjects reported the use of tobacco long before the first interview, opening the potential for recall bias. Analyses 
restricting the sample to subjects who developed symptoms after the study began did not alter the results. ${ }^{28}$ The short latencies cannot be attributed to postulated defects in individual survey items, since very short latencies were observed for all 11 survey items. ${ }^{28}$

The possibility that youths were reporting false symptoms as a result of prompting brought about by a desire to show off, a desire to please the interviewer, or expectations about nicotine dependence derived from sociocultural influences was considered. We have not found evidence of such expectations in adolescent focus groups (DiFranza JR, et al, unpublished data). These explanations are inconsistent with observations that the report of one or more symptoms was a strong predictor of failed cessation, continued smoking, and daily smoking, and are inconsistent with the observed correlations between the number of reported symptoms and the maximum amount and frequency of smoking. ${ }^{20}$ Expectations do not explain why youths experience difficulty quitting so soon after the onset of use since youths hold unrealistic expectations about the ease of quitting. ${ }^{48}$ Thus, we were unable to explain the observed results based on methodological problems.

Further support for the validity of the data comes from its consistency with previous studies reporting withdrawal symptoms among youths who were not smoking daily at the time of the interview, and a report that $8 \%$ of subjects who had smoked 20 or fewer cigarettes over their lifetime had difficulty quitting. ${ }^{12} 3132$ These cross sectional studies were not subject to potential biases because of repeated interviewing.

In this study, girls reported more numerous symptoms of dependence and a much more rapid onset of symptoms. This was not caused by sex differences in attrition. Girls did not report more symptoms from their first inhalation such as dizziness or cough; there was no evidence that they over report symptoms generally. ${ }^{75}$ Sex differences in responses to nicotine in humans and animals have been recently reviewed.$^{76}$ While some sex effects have been observed, they do not present a consistent pattern. At the lowest doses, female rats have acquired self administration of nicotine faster than males. ${ }^{77}$ Females were willing to lever press at higher rates than males to obtain nicotine, were quicker to earn their first dose of nicotine after a 23 hour period of deprivation, and displayed more pronounced sensitisation to the behavioural effects of nicotine. ${ }^{77}$ Using a modified version of the Fagerstrom Tolerance Questionnaire, Rojas and colleagues reported that male adolescents smoked more heavily and scored slightly more dependent than females, but they did not see any sex differences in the number of nicotine withdrawal symptoms or their frequency ${ }^{78}$ Stanton reported that female adolescents were more likely to smoke to relieve withdrawal symptoms. ${ }^{79}$ Further study is needed to reconcile these differences and explore possible mechanisms.

The strengths of the DANDY study include a prospective design, a large diverse population (332 tobacco users, 237 inhalers), and an unselected sample evaluated in their natural environment over several years. Many studies of nicotine withdrawal symptoms among adults have been performed with only 20-50 highly selected subjects in laboratory settings. ${ }^{13-15}{ }^{80}$ With its frequent follow up and use of memory aides to collect dates for events, this study is far more rigorous than any previously reported study concerning the timing of smoking events, some of which have required recall periods of 20 years or more. ${ }^{81} 82$

The higher attrition rate for subjects whose parents had smoked may have contributed to our inability to demonstrate any role of parental smoking in the onset of symptoms of dependence. The principal challenge to the interpretation of our results is the lack of consensus regarding what marks the onset of dependence. There is disagreement as to whether all of the items in table 1 are symptoms of dependence. All had been used as indicators of dependence, but in the absence of a gold standard for dependence, the validation of these items

\section{What this paper adds}

It has been widely assumed that moderate daily use of tobacco over an extended period of time is a prerequisite for nicotine dependence. The Development and Assessment of Nicotine Dependence in Youth (DANDY) study contradicts this view, with results indicating that the first symptoms of nicotine dependence can appear within a matter of days or weeks of the onset of intermittent tobacco use. These first symptoms were strongly predictive of long term tobacco use, indicating that the loss of autonomy over tobacco can occur very rapidly with minimal exposure to nicotine. The DANDY study has important implications for prevention strategies, cessation programmes, the measurement of nicotine dependence in youths, animal models of the neurobiology of nicotine dependence, and regulations intended to reduce the addiction potential of tobacco products.

has typically been against some measure of nicotine intake or the ability to control use..$^{12} 3134783$ The withdrawal items have been validated for adolescents against cotinine concentrations (a metabolite of nicotine). ${ }^{12}$ The item concerning smoking in forbidden places, adapted from the Fagerstrom Tolerance Questionnaire, also had been validated against cotinine concentrations. "Needing" tobacco has been widely cited as a symptom of dependence, ${ }^{12} 333536$ and correlates very closely with the inability to control consumption. ${ }^{36}$ Craving as a manifestation of nicotine withdrawal has been documented in a laboratory setting. ${ }^{13}{ }^{14}$ Absent another methodological flaw, it would be necessary to reject all 11 items in table $1^{1}$ as symptoms of dependence to avoid the conclusion that symptoms develop quickly. ${ }^{28}$

Current criteria for nicotine dependence define the point when the use of tobacco represents a mental disorder. ${ }^{3}$ We feel that the loss of autonomy over tobacco represents a broader and more useful measure of the onset of dependence among adolescents. Youths can lose their autonomy over tobacco use-that is, they can get hooked, very quickly and at very low levels of nicotine exposure. Despite the rapidity with which the first symptom can appear, the presence of a single symptom of dependence strongly predicts that the initial attempt at cessation will be unsuccessful (OR $=29)$. An estimated 32\% of all young smokers ultimately die prematurely as a result of their tobacco use. ${ }^{84}$ For some victims of tobacco, their unfortunate fates may have been cast with their first few cigarettes.

\section{ACKNOWLEDGEMENT}

This study was funded by grant number CA77067-03 from the National Cancer Institute. The opinions expressed in this paper are those of the authors and do not necessarily represent the official views of the National Cancer Institute.

\section{Authors' affiliations}

J R DiFranza, J A Savageau, K Fletcher, J K Ockene, M Coleman,

C Wood, University of Massachusetts Medical School, Worcester, Massachusetts, USA

N A Rigotti, Harvard Medical School, Massachusetts, USA

A D McNeill, University of London, London, UK

\section{REFERENCES}

1 Watkins SS, Koob GF, Markou A. Neural mechanisms underlying nicotine addiction: acute positive reinforcement and withdrawal. Nicotine and Tobacco Research 2000;2:19-37.

2 Leonard S, Breese CR, Adams CE, et al. Regulation of nicotinic receptors in schizophrenic smokers: measurement of receptor levels in postmortem brain and peripheral blood cells. Abstract SYM 3C presented at the sixth annual meeting of the Society for Research on Nicotine and Tobacco. February, 2000.

3 American Psychiatric Association. Diagnostic and statistical manual of mental disorders: DSM-IV. 4th ed. Washington DC: American Psychiatric Association, 1994. 
4 US Department of Health and Human Services. The health consequences of smoking: nicotine addiction. A report of the Surgeon General, 1988. Rockville, Maryland: Public Health Service, Centers for Disease Control, Office on Smoking and Health, 1988. (DHHS Publication No (CDC) 88-8406.)

5 Pomerleau CS, Majchrzak M, Pomerleau OF. Nicotine dependence and the Fagerstrom tolerance questionnaire: a brief review. J Substance Abuse 1989;1:471-7

6 World Health Organization. International statistical classification of diseases and related health problems, 10th revision. Geneva: WHO, 1992

7 American Psychiatric Association. Diagnostic and statistical manual of mental disorders: DSM-III-R, 3rd ed. Washington DC: American Psychiatric Association, 1987

8 Colby SM, Tiffany ST, Shiffman S, et al. Measuring nicotine dependence among youth: a review of available approaches and instruments. Drug and Alcohol Dependence 2000;59(suppl 1):S23-39.

9 Hughes JR. Nicotine withdrawal, dependence, and abuse. DSM-IV sourcebook, chapter 7. Washington DC: American Psychiatric Association, 1998:109-16

10 Edwards G, Gross MM. Alcohol dependence: provisional description of a clinical syndrome. BM 1976;i:1058-61.

11 Rounsaville BJ, Spitzer RL, Williams JBW. Proposed changes in DSM-III substance use disorders: description and rationale. Am J Psychiatry 1986; 143:463-8.

12 McNeill AD, West RJ, Jarvis $M$, et al. Cigarette withdrawal symptoms in adolescent smokers. Psychopharmacology 1986;90:533-6.

13 Hatsukami DK, Hughes JR, Pickens RW, et al. Tobacco withdrawal symptoms: an experimental analysis. Psychopharmacology 1984;84:231-6.

14 Hatsukami DK, Gust SW, Keenan RM. Physiologic and subjective changes from smokeless tobacco withdrawal. Clin Pharmacol Ther 1987;41:103-7

15 Hughes JR, Hatsukami DK. Signs and symptoms of tobacco withdrawal. Arch Gen Psychiatry 1986;43:289-94.

16 Robinson TE, Berridge KC. The neural basis of drug craving: an incentive-sensitization theory of addiction. Brain Research Reviews 1993; 18:247-91

17 Fagerstrom KO, Heatherton TF, Kozlowski LT. Nicotine addiction and its assessment. Ear Nose Throat J 1990;69:763-6.

18 Cottler LB, Schuckit MA, Helzer JE, et al. DSM-IV sourcebook, vol 4, chapter 38. Washington DC: American Psychiatric Association.

19 Pomerleau CS, Carton SM, Lutzke ML, et al. Reliability of the Fagerstrom tolerance questionnaire and the Fagerstrom test for nicotine dependence. Addict Behav 1994:19:33-9.

20 DiFranza JR, Savageau JA, Fletcher K, et al. Measuring the loss of autonomy over nicotine use in adolescents: the development and assessment of nicotine dependence in youths (DANDY) study. Arch Pediatr Adolesc Med 2002;156:397-403.

21 Leventhal H, Cleary PD. The smoking problem: a review of the research and theory in behavioral risk modification. Psychol Bull 1980;88:370-405.

22 Wang MQ, Fitzhugh EC, Eddy JM, et al. Attitudes and beliefs of adolescent experimental smokers: a smoking prevention perspective. J Alcohol Drug Educ 1996;41:1-12.

23 Jackson C. Cognitive susceptibility to smoking and initiation of smoking during childhood: a longitudinal study. Prev Med 1998;27:129-34.

24 Lamkin L, Houston TP. Nicotine dependency and adolescents: preventing and treating. Adolesc Med 1998;25:123-35.

25 Chassin L, Presson CC, Sherman SJ, et al. The natural history of cigarette smoking: predicting young-adult smoking outcomes from adolescent smoking patterns. Health Psychol 1990;9:701-16.

26 Evans NJ, Gilpin E, Pierce JP, et al. Occasional smoking among adults: evidence from the California tobacco survey. Tobacco Control 1992;1:169-75.

27 Shiffman S. Refining models of dependence: variations across persons and situations. Br J Addiction 1991;86:611-15.

28 Difranza JR, Rigotti NA, McNeill AD, et al. Initial symptoms of nicotine dependence in adolescents. Tobacco Control 2000;9:313-19.

29 US Department of Health and Human Services. Massachusetts 1996, selected demographic information Massachusetts and United States. Atlanta, Georgia: Centers for Disease Control, 1996.

30 Abt Associates. Independent evaluation of the Massachusetts tobacco control program, January 1994 to June 1995. Cambridge Massachusetts: Abt Associates, 1996.

31 Barker D. Reasons for tobacco use and symptoms of nicotine withdrawal among adolescent and young adult tobacco users - United States, 1993. MMWR Morb Mortal Wkly Rep 1994;43:745-50

32 Goddard E. Why children start smoking. Office of population censuses and surveys. London:HMSO, 1990

33 Dappen A, Schwartz RH, O'Donnell R. A survey of adolescent smoking patterns. J Am Board Fam Pract 1996;9:7-13.

34 Henningfield JE, Clayton R, Pollin W. Involvement of tobacco in alcoholism and illicit drug use. Br J Addiction 1990;85:279-92.

35 Henningfield J. Symptoms of substance dependence associated with use of cigarettes, alcohol, and illicit drugs - United States, 1991-1992. MMWR Morb Mortal Wkly Rep 1995;44:830-1, 837-9.

36 Gfroerer J. Indicators of nicotine addiction among women-United States, 1991-1992. MMWR Morb Mortal Wkly Rep 1995;44:102-5.

37 O'Loughlin J, Tarasuk J, DiFranza J, et al. Validation of selected measures of nicotine dependence among adolescents. Ann Epidemiol (in press).
38 O'Loughlin J, Kishchuck N, DiFranza J, et al. The hardest thing is the habit: a qualitative investigation of adolescent smokers' experience of nicotine dependence. Nicotine and Tobacco Research (in press).

39 Bradburn NM, Rips L, Shevell SK. Answering demographic questions: the impact of memory and inference on surveys. Science 1987:236:157-61

40 Ershler J, Leventhal $H$, Fleming $R$, et al. The quitting experience for smokers in sixth through twelfth grades. Addict Behav 1989;14:365-78.

41 SPSS INC. SPSS Base 10.0. Chicago, Illinois: SPSS Inc, 1999.

42 Johnston LD, O'Malley PM, Bachman JG. Monitoring the fture national survey results on drug use, 1975-2000. Volume I: Secondary school students. Bethesda, Maryland: National Institute on Drug Abuse, 2001 (NIH Pub No. 01-4924)

43 Bayer SA, Yackel JW, Puri PS. Neurons in the rat dentate gyrus granular layer substantially increase during juvenile and adult life. Science 1982:216:890-2

44 Altman J, Bayer SA.Migration and distribution of two populations of hippocampal granule cell precursors during the perinatal and postnatal periods. J Comp Neurol 1990;301:365-81.

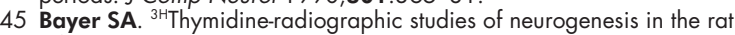
olfactory bulb. Exp Brain Res 1983;50:329-40.

46 McWilliams JR, Lynch G. Rate of synaptic replacement in denervated rat hippocampus declines precipitously from the juvenile period to adulthood. Science 1983;221:572-4

47 US Department of Health and Human Services. Preventing tobacco use among young people. A report of the Surgeon General, 1994. Atlanta, Georgia: Public Health Service, Centers for Disease Control and Prevention, Office on Smoking and Health, 1994. (US Government Printing Office Publication No S/N 017-001-00491-0.)

48 Colby SM, Tiffany ST, Shiffman S, et al. Are adolescent smoker dependent on nicotine? A review of the evidence. Drug Alcohol Depend 2000;59(suppl 1):S83-95

49 Breslau N, Fenn N, Peterson EL. Early smoking initiation and nicotine dependence in a cohort of young adults. Drug Alcohol Depend 1993;33: 129-37

50 Taioli E, Wynder EL. Effect of the age at which smoking begins on frequency of smoking in adulthood. N Engl J Med 1991;325:968-9.

51 Chen J, Millar WJ. Age of smoking initiation: implications for quitting. Health Reports 1998;9:39-46.

52 Escobedo LG, Marcus SE, Holtzman D, et al. Sports participation, age at smoking initiation, and the risk of smoking among US high school students. JAMA 1993;269:1391-5.

53 Everett SA, Warren CW, Sharp D, et al.Initiation of cigarette smoking and subsequent smoking behavior among US high school students. Prev Med 1999;29:327-33.

54 Smith TA, House RF, Croghan IT, et al. Nicotine patch therapy in adolescent smokers. Pediatrics 1996;98:659-67.

55 Hurt RD, Croghan GA, Beede SD, et al. Nicotine patch therapy in 101 adolescent smokers. Arch Pediatr Adolesc Med 2000;154:31-7.

56 Trauth JA, Seidler FJ, McCook EC, et al. Adolescent nicotine exposure causes persistent upregulation of nicotinic cholinergic receptors in rat brain regions. Brain Res 1999;851:9-19.

57 Trauth JA, Seidler FJ, Ali SF, et al. Adolescent nicotine exposure produces immediate and long-term changes in CNS noradrenergic and dopaminergic function. Brain Res (in press).

58 Trauth JA, McCook EC, Seidler FJ, et al. Modeling adolescent nicotine exposure: effects on cholinergic systems in rat brain regions. Brain Res 2000;873:18-25.

59 Trauth JA, Seidler FJ, Slotkin TA. An animal model of adolescent nicotine exposure: effects on gene expression and macromolecula constituents in rat brain regions. Brain Res 2000;867:29-39.

60 Kelley BM, Middaugh LD. Periadolescent nicotine exposure reduces cocaine reward in adult mice. J Addict Dis 1999;18:27-39

61 Trauth JA, Seidler FJ, Slotkin TA. Persistent and delayed behavioral changes after nicotine treatment in adolescent rats. Brain Res 2000;880: 167-72

62 Faraday MM, Elliott BM, Grunberg NE. Nicotine's behavioral actions differ in adult vs adolescent rats. Abstract PO 3-16 presented at the sixth annual meeting of the Society for Research on Nicotine and Tobacco. February 2000 .

63 Dozios DN, Farrow JA, Miser A. Smoking patterns and cessation motivations during adolescence. Int J Addictions 1995;30: 1485-98.

64 Albrecht SA, Braxter B, Allison BA, et al. Predictors of smoking cessation among pregnant teens. Abstract PO 3-3 presented at the sixth annual meeting of the Society for Research on Nicotine and Tobacco. February 2000.

65 Parrott AC. Stress modulation over the day in cigarette smokers. Addiction 1995;90:233-44

66 Gilbert DG, Robinson JH, Chamberlin CL, et al. Effects of smoking/nicotine on anxiety, heart rate, and lateralization of EEG during a stressful movie. Psychophysiology 1989;26:311-20.

67 Mansvelder HD, McGehee DS. Long-term potentiation of excitatory inputs to brain reward areas by nicotine. Neuron 2000;27:349-57

68 Benwell ME, Balfour DJK, Anderson JM. Evidence that tobacco smoking increases the density of $[-]-[3 \mathrm{H}]$ nicotine binding sites in human brain. $J$ Neurochem 1988:50:1243-7.

69 Ksir C, Hakan R, Hall DP, et al. Exposure to nicotine enhances the behavioral stimulant effect of nicotine and increases binding of $[3 \mathrm{H}]$ acetylcholine to nicotinic receptors. Neuropharmacology 1985;24:527-3

70 Marks MJ, Stitzel JA, Collins AC. Time course study of the effects of chronic nicotine infusion on drug response and brain receptors. $J$ Pharmacol Exp Ther 1985;235:619-28. 
71 Schwartz RD, Kellar KJ. In vivo regulation of [3H]acetylcholine recognition sites in brain by nicotinic cholinergic drugs. J Neurochem 1985;45:427-33.

72 Picciotto MR, Caldarone BJ, King SL, et al. Molecular mechanisms relevant to psychosis and nicotine dependence: use of transgenic mouse model to explore the biology of nicotinic receptors. Abstract SYM 3A presented at the sixth annual meeting of the Society for Research on Nicotine and Tobacco. February 2000.

73 Wonnacott S. The paradox of nicotinic acetylcholine receptor upregulation. Trends Pharmacol Sci 1990;11:216-19.

74 Lapchak PA, Araujo DM, Quirion R, et al. Effect of chronic nicotine treatment on nicotinic autoreceptor function and $\mathrm{N}-[3 \mathrm{H}]$ Methylcarbamylcholine binding sites in the rat brain. J Neurochem 1989;52:483-91.

75 Di Franza JR, Savageau JA, Fletcher K, et al. Recollections and repercussions of the first inhaled cigarette. Addictive Behaviours (in press).

76 Perkins KA, Donny E, Caggiula AR. Sex differences in nicotine effects and self-administration: review of human and animal evidence. Nicotine and Tobacco Research 1999;1:301-15.
77 Donny EC, Caggiula AR, Rowell PP, et al. Nicotine self-administration in rats: estrous cycle effects, sex differences and nicotinic receptor binding. Psychopharmacology 2000;151:392-405

78 Rojas NL, Killen JD, Haydel KF, et al. Nicotine dependence among adolescent smokers. Arch Pediatr Adolesc Med 1998;152:151-6.

79 Stanton WR. DSM-III-R tobacco dependence and quitting during late adolescence. Addict Behav 1995;20:595-603.

80 Hatsukami DK, Hughes JR, Pickens RW. Blood nicotine, smoke exposure and tobacco withdrawal symptoms. Addict Behav $1985 ; 10: 413-17$

81 Gfroerer J. Indicators of nicotine addiction among women - United States, 1991-1992. MMWR Morb Mortal Wkl Rep 1995;44:102-5.

82 Breslau N Peterson EL. Smoking cessation in young adults: age at initiation of cigarette smoking and other suspected influences. Am J Public Health 1996:86:214-20.

83 Prokhorov AV, Pallonen UE, Fava JL, et al. Measuring nicotine dependence among high-risk adolescent smokers. Addict Behav 1996;21:117-27.

84 Durham J, Owen P, Bender B, et al. Projected smoking-related deaths among youth - United States. MMWR Morb Mortal Wkly Rep 1996:45:971-5.

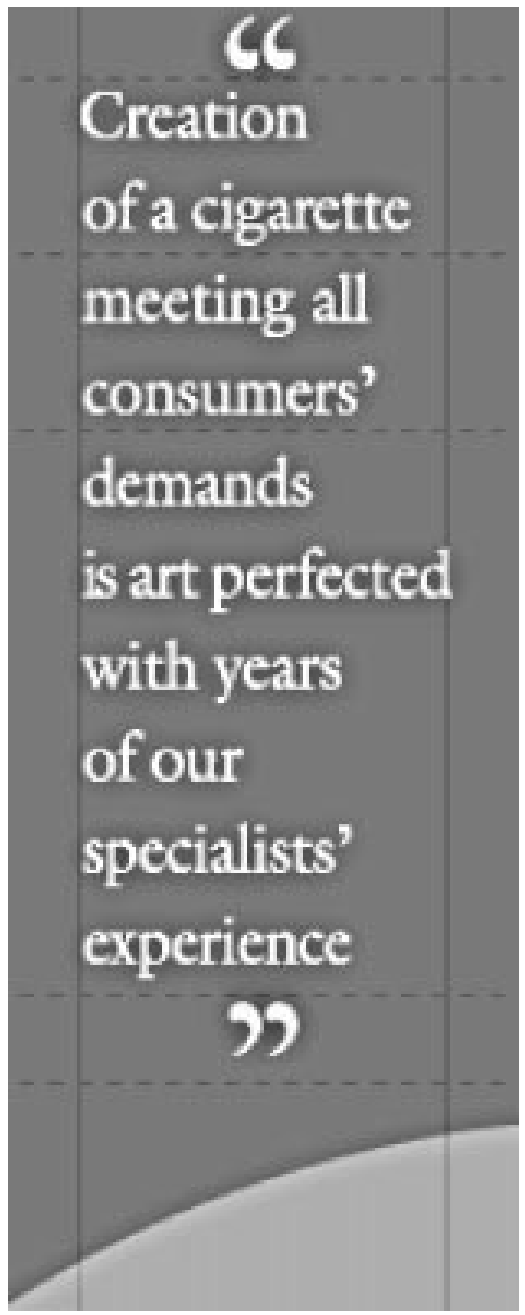

Making carcinogenic, addictive cigarettes is now an "art", according to BAT Russia. 